\title{
Characteristics of Single Aerosol Particles during Pollution in Winter in an Urban Area of Ningbo, China
}

\author{
Meng-Rong Yang ${ }^{1,2,3+}$, Jun Zhou ${ }^{4+}$, Xiao-Rong Dai ${ }^{1,3}$, Dominik van Pinxteren ${ }^{5}$, Ming-Yang Cao ${ }^{6}$, \\ Mei $\mathrm{Li}^{7 * *}$, Hang Xiao ${ }^{1,3^{*}}$ \\ ${ }^{1}$ Center for Excellence in Regional Atmospheric Environment, Institute of Urban Environment, Chinese Academy of \\ Sciences, Xiamen 361021, China \\ ${ }^{2}$ University of Chinese Academy of Sciences, Beijing 100049, China \\ ${ }^{3}$ Ningbo Urban Environment Observation and Research Station-NUEORS, Chinese Academy of Sciences, Ningbo 315830 , \\ China \\ ${ }^{4}$ Environment monitoring Center of Ningbo, Ningbo 315012, China \\ ${ }^{5}$ Leibniz-Institut für Troposphärenforschung (TROPOS), Permoserstr.15, 04318 Leipzig, Germany \\ ${ }^{6}$ Guangzhou Hexin Analytical Instrument Limited Company, Guangzhou 510530, China \\ ${ }^{7}$ Institute of Mass Spectrometer and Atmospheric Environment, Jinan University, Guangzhou 510632, China
}

\begin{abstract}
The size and composition of individual atmospheric particles were assessed using a single particle aerosol mass spectrometer in Ningbo, China, from 30 December 2016 to 12 January 2017. The particles were primarily carbonaceous and inorganic, with the majority $(60 \%)$ being carbonaceous. All of the major particle types contained internally mixed secondary species, such as nitrate and sulfate. The temporal trends of the particle number concentrations and $\mathrm{PM}_{2.5}$ (particulate matter with an aerodynamic diameter $<2.5 \mu \mathrm{m}$ ) mass concentrations indicated that secondary formation in Ningbo severely affected the air quality. The sampling period was divided into three subperiods according to the $\mathrm{PM}_{2.5}$ mass concentration. During Period I, local emission and secondary formation were the primary contributors of the pollution, and during Periods II and III, the abundance of particles occurring with high-speed winds indicated that regional transport was a primary factor in these two pollution processes. Additionally, high $\mathrm{PM}_{2.5}$ mass concentrations were often observed at night during high relative humidity and low temperatures across the entire sampling period. These results demonstrate that stagnant meteorological conditions increase pollution during winter. Overall, this study enhances our understanding of particulate pollution in the southern Yangtze River Delta region and provides useful information on the formation and growth of atmospheric aerosols.
\end{abstract}

Keywords: Particulate matter; Mixing state; Mass spectral characteristics; Size distribution.

\section{INTRODUCTION}

$\mathrm{PM}_{2.5}$ (particles with diameter $<2.5 \mu \mathrm{m}$ ) has profound impacts on human health, atmospheric visibility, and global climate (Kanakidou et al., 2005; Tie et al., 2009). The Yangtze River Delta (YRD) region, which includes areas

\footnotetext{
${ }^{+}$These authors contributed equally to this work.

* Corresponding author.

Tel.: + $8657486784813 ;$ Fax: + 8657486784813

E-mail address: hxiao@iue.ac.cn

** Corresponding author.

Tel.: +86 020 85220220; Fax: +8602085220220

E-mail address: limei2007@163.com
}

of Shanghai, southern Jiangsu Province, and northern Zhejiang Province, is subject to severe gaseous pollutants and particulate matter contamination. Numerous studies have revealed high $\mathrm{PM}_{2.5}$ concentration and low visibility in the YRD region (Gao et al., 2011; Cheng et al., 2014; Wang et al., 2014), particularly during winter. Ningbo is a coastal city in Zhejiang Province, which is in the southeast YRD region. In 2015, according to the Environment Status Report of Ningbo, the annual average of $\mathrm{PM}_{2.5}$ was up to $45 \mu \mathrm{g} \mathrm{m}^{-3}$, which is higher than the secondary permissible limits provided in the National Ambient Air Quality Standards of China (NAAQS; $35 \mu \mathrm{g} \mathrm{m}^{-3}$, GB 3095-2012). $\mathrm{PM}_{2.5}$ was the primary air pollutant in Ningbo. The concentrations of $\mathrm{SO}_{2}, \mathrm{NO}_{2}, \mathrm{PM}_{10}, \mathrm{CO}$, and $\mathrm{PM}_{2.5}$ were higher in winter and lower in summer (Chai and Zheng, 2018).

Information on aerosol particle size and chemical 
species is crucial for monitoring and characterizing air pollution. A single particle aerosol mass spectrometer (SPAMS) was invented based on time-of-flight mass spectrometry, and SPAMS provides continuous, real-time, and size-resolved information on the mixing state and chemical composition of single particles (Li et al., 2017). It is a powerful instrument for capturing information on the chemical and physical properties, mixing states, sources, and atmospheric processing of single particles (Zhou et al., 2016; Zhao et al., 2017). This tool is extremely advantageous for understanding the formation mechanisms of aerosols and their impact on local and global climate. To obtain a thorough understanding of the single particle size distribution, chemical composition, and mixing state of aerosol particles, Bi et al. (2011) studied the mixing state of aerosol particles in the urban area of the Pearl River Delta (PRD) and revealed that $90 \%$ of biomass burning particles are internally mixed with secondary inorganic species. Wang et al. (2016) reported that the amount of elemental carbon (EC) particles in the environment with a diameter range of $0.65-1.4 \mu \mathrm{m}$ increased to $25 \%$ of all particles on hazy days in Nanjing. Yang et al. (2012) studied heavy haze periods in the YRD region and indicated that carbon signals were associated with ammonium nitrate, which changed the mixing state of particles, enhanced light extinction, and degraded visibility.

Previous studies on aerosol particles in Ningbo have conducted sampling across $12-24$ periods by using conventional off-line techniques ( $\mathrm{Xu}$ et al., 2016). Few real-time analyses of single particles in Ningbo have been performed. In order to determine particle sources and observe the evolution of pollutants, it is necessary to determine their chemical and physical properties. In this study, a SPAMS was employed to characterize the chemical composition, size distribution, and mixing state of each aerosol particle. Distinctive mass spectral signatures, aging processes, and possible sources of major particle types were studied during the observation period in the municipal area of Ningbo in winter. This study may provide an understanding of the process of atmospheric pollution from the perspective of single particles.

\section{EXPERIMENTAL METHODS}

\section{Sampling Site}

A SPAMS (Hexin Analytical Instrument Co., Ltd., Guangdong, China) was installed on the roof of Zhenghai Library $(29.96 \mathrm{~N}, 121.72 \mathrm{E})$ in the northeast of Ningbo city (Fig. 1), which is about $3 \mathrm{~km}$ from the East China Sea. A $\mathrm{PM}_{2.5}$ cyclone inlet was employed. A typical urban area surrounded by residential and commercial communities was used for sampling. The sampling site is primarily impacted by traffic emission, residential cooking, and industrial sources (Xiao et al., 2012). This study determined the size and composition of each atmospheric particle sampled from 30 December 2016 to 12 January 122017.

\section{Single Particle Acquisition and Data Analysis}

In this study, the SPAMS was used for recording the diameter distribution and mass spectra of each particle. Previous studies have provided detailed information on the SPAMS (Li et al., 2011; Yang et al., 2017a). In general, particles are introduced into a vacuum system through a critical orifice of $100 \mu \mathrm{m}$ at a flow rate of $100 \mathrm{~mL} \mathrm{~min}^{-1}$ and pressure of 2.2 torr and are then steadily focused on the axis of an aerodynamic lens. Some particles then undergo velocity distribution based on their aerodynamic size. After passing two continuous wave lasers of $532 \mathrm{~nm}$, the sized particles reach an ionization area, where positive and

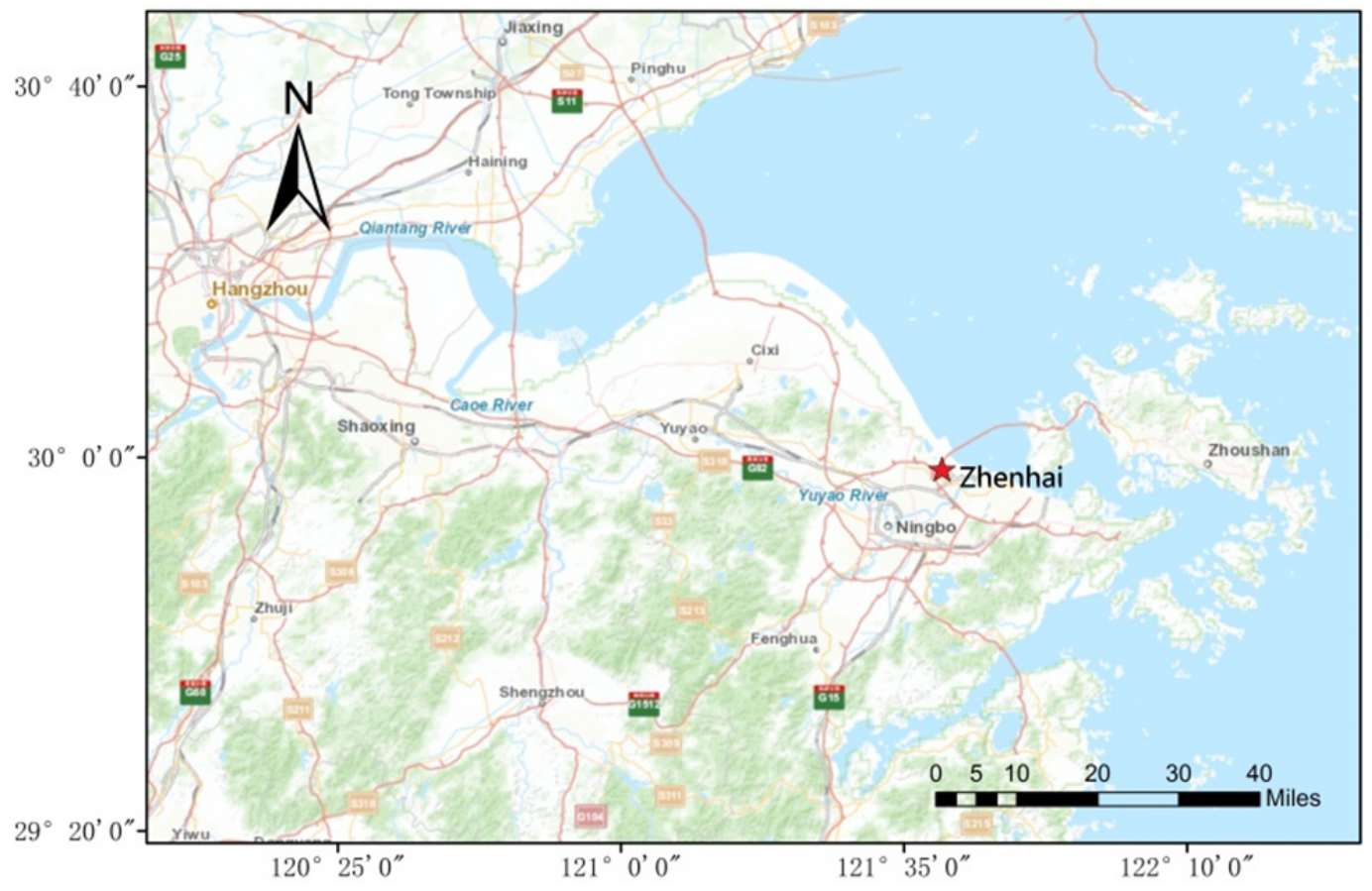

Fig. 1. Sampling site in Ningbo. 
negative ions are produced by a 266-nm Nd:YAG laser (hit particle). Finally, ions are detected using a bipolar time-offlight mass spectrometer. The diameters $(0.23,0.32,0.50$, $0.74,0.96,1.4$, and $2.0 \mu \mathrm{m}$ ) of standard polystyrene latex particles were used to calibrate particle size. A small quantity of ions of $\mathrm{Li}, \mathrm{Na}, \mathrm{K}, \mathrm{V}, \mathrm{Ba}$, and $\mathrm{Pb}$ were used for mass spectrum calibration. The laser power was kept at $0.8 \times 10^{8}$ $\mathrm{W} \mathrm{cm}{ }^{-2}$ and the particle average hit rate was $12.23 \%$.

In this study, the data were analyzed using MATLAB (The MathWorks Inc., Natick, Massachusetts, USA) and were introduced into COCO_P, which is a MATLAB-based software toolkit for handling data sets. Data was classified by an adaptive resonance theory-neutral algorithm (ART-2a). The parameters of an ART-2a analysis were a learning rate and vigilance factor of 0.05 and 0.65 , respectively. There was a maximum of 20 iterations. This study examined particles with a vacuum aerodynamic diameter $\left(\mathrm{d}_{\mathrm{va}}\right)$ of 0.2-2.5 $\mu \mathrm{m}$, which were more effectively detected.

\section{RESULTS AND DISCUSSION}

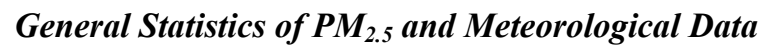

During the SPAMS measuring period, the average $\mathrm{PM}_{2.5}$ mass concentration and meteorological data were obtained from the Longsai Hospital monitoring station (29.96 N, 121.72 E) and provided by Environment Monitoring Center of Ningbo. Meteorological data included temperature $\left(\mathrm{T},{ }^{\circ} \mathrm{C}\right)$, relative humidity $(\mathrm{RH}, \%)$, wind direction (WD), and wind speed (WS). Fig. 2 shows the temporal profiles (in 5-min resolution) of $\mathrm{PM}_{2.5}$ and meteorological parameters. The average and maximum hourly $\mathrm{PM}_{2.5}$ concentrations were 52.3 and $147.0 \mu \mathrm{g} \mathrm{m}^{-3}$, respectively. The ambient $\mathrm{T}$, $\mathrm{RH}$, and WS during the field study were $5.6-17.9^{\circ} \mathrm{C}, 61-$ $100 \%$, and $0-7.3 \mathrm{~m} \mathrm{~s}^{-1}$, with average values of $10.7^{\circ} \mathrm{C}$, $85.4 \%$, and $2.2 \mathrm{~m} \mathrm{~s}^{-1}$, respectively. Temperature and humidity exhibited opposite trends during the observation period. Wind from the northwest had a higher speed than that from other directions. On the basis of the change in $\mathrm{PM}_{2.5}$ mass concentrations, the observation time was divided into three periods. During Period I, from 30 December 2016 to 1 January 2017, temperature and RH showed evident diurnal variations with average values of $10.7^{\circ} \mathrm{C}$ and $85.4 \%$, respectively. $\mathrm{PM}_{2.5}$ mass concentration reached its two highest values at night under low WS. In Period II, from 1 January 2017 to 5 January 2017, PM $_{2.5}$ mass concentration produced moderate pollution during daytime under a high WS of the northern wind. In Period III, from 7 January 2017 to 11 January 2017 , low temperature and RH were observed.

\section{Mass spectral Characteristics of Major Particle Types}

In total, 632,768 particles were hit, and 361,533 particles with positive and negative mass spectra were acquired, which were further classified using the ART-2a algorithm. Subsequently, 855 clusters were obtained, and the first 289 clusters comprised more than $96 \%$ of the total particles. According to the most significant chemical features in positive and negative mass spectral signatures and consulting the relevant literature (Fu et al., 2014; Cai et al., 2015), the

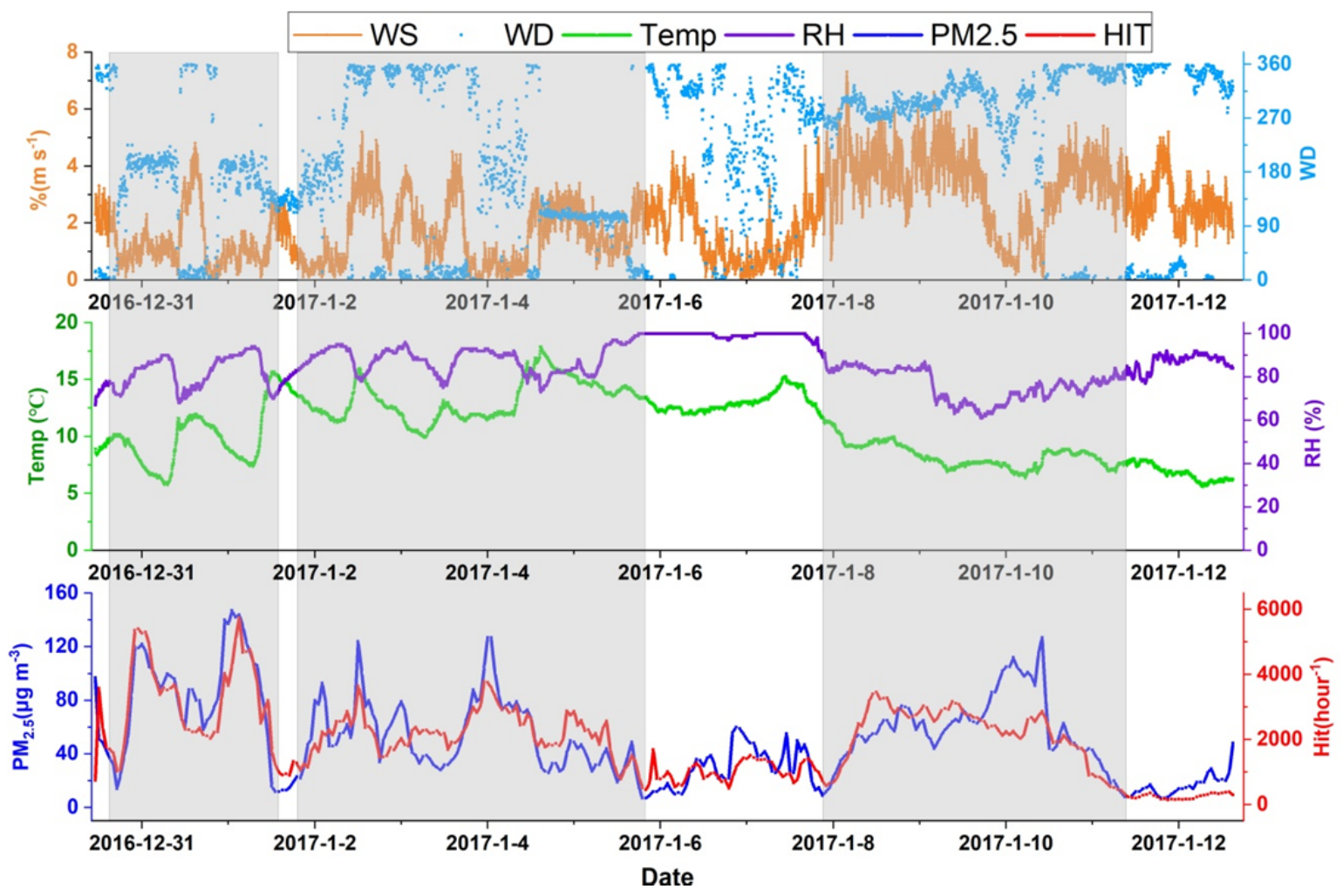

Fig. 2. Temporal profiles (in 1-h resolution) of $\mathrm{PM}_{2.5}$ mass concentration and hit particle number concentration and temporal profiles (in 5-min resolution) of meteorological parameters, namely temperature (T), relative humidity (RH), wind direction (WD), and wind speed (WS) (three periods in the grey area). 
first 289 clusters were manually combined into 9 major types of clusters, namely EC, organic carbon (OC), particles combining EC and OC (ECOC), high-molecular-weight organic carbon (HOC), levoglucosan (LEV), potassium-rich (K-rich), heavy metal (HM), sodium-rich (Na-rich), and dust particles (dust). Fig. 3 shows the average positive and negative mass spectra of these particle types.

\section{Carbonaceous Types}

During the sampling period, carbonaceous particles were dominant $(60.0 \%)$ and included four subtypes: EC, $\mathrm{OC}, \mathrm{ECOC}$, and HOC.

EC is defined by the $\mathrm{m} / \mathrm{z} 12$ interval of a carbon ion cluster in both positive and negative mass spectra in Fig. 3(a). Table 1 shows that the average number of EC particles comprised $46.9 \%$ of the total ionized particles. In previous studies, a high fraction of EC containing particles was observed in other regions worldwide (Cahill et al., 2012; Fu et al., 2012; Zhang et al., 2014). EC particles were separated into fresh EC and aged EC. Fresh EC was from primary emissions of road traffic, while aged EC may have been due to long-range transportion (Giorio et al., 2012, 2015). Na-EC particles were observed in vehicle exhaust (Toner et al., 2006). The monitoring station is located in a heavily trafficked area. From Fig. S1, smaller EC particles $(<0.45 \mu \mathrm{m})$ and $\mathrm{NO}_{2}$, which are traffic related pollutants, have similar time profiles; thus, vehicle emission may be the principal local source of EC particles. The data set was divided into two size ranges $(<0.45 \mu \mathrm{m}$ and $>1 \mu \mathrm{m})$ (Fig. 9). The relative intensity of the signal of $\mathrm{CN}^{-}$in $\mathrm{EC}$ particles smaller than $0.45 \mu \mathrm{m}$ is twice of that in EC particles larger than $1 \mu \mathrm{m}$, which may be related to primary emission from incomplete combustion. Larger EC particles $(>1 \mu \mathrm{m})$ were dominated by secondary species peaks of $\mathrm{NO}_{2}^{-}, \mathrm{NO}_{3}^{-}$, and $\mathrm{HSO}_{4}^{-}$in the negative mass spectrum, thus indicating that these particles underwent an aging process. As seen in Fig. S3, larger EC particles mainly were transported from northwest of the sampling point.

In this study, $1.2 \%$ of absolute particles were ECOC particles, and these particles contained carbon ion clusters $(\mathrm{m} / \mathrm{z}$ of $12 / 24 / 36)$ (e.g., EC) and typical oxidized OC fragments (e.g., $\mathrm{C}_{2} \mathrm{H}_{3} \mathrm{O}^{+}$). The secondary ion species of ECOC particles in (Fig. 3(b)), such as nitrate and sulfate, indicate aging in the atmosphere. ECOC was generally produced primarily by the coagulation of $\mathrm{EC}$ particles with volatile organics. The concentration of sulfate in ECOC was slightly higher than that of nitrate. Primary nitrate and sulfate are associated with traffic emissions or residential wood smoke production (Taiwo et al., 2014) and with coke-making emissions, sinters, and blast furnace factories (Konieczynski et al., 2012), respectively. In addition to the conversion of EC particles, ECOC has other sources.

In total, $6.6 \%$ of the analyzed particles comprised OC particles. An OC positive mass spectrum comprised hydrocarbon ion fragments (Fig. 3(c)), such as $\mathrm{C}_{2} \mathrm{H}_{3}{ }^{+}(\mathrm{m} / \mathrm{z}$ of 27), $\mathrm{C}_{4} \mathrm{H}_{3}{ }^{+}$(m/z of 51), $\mathrm{C}_{5} \mathrm{H}_{3}{ }^{+}$(m/z of 65), $\mathrm{C}_{6} \mathrm{H}_{5}{ }^{+}(\mathrm{m} / \mathrm{z}$ of 91 ), and $\mathrm{C}_{2} \mathrm{H}_{3} \mathrm{O}^{+}$(m/z of 43 ). The negative spectrum of OC was similar to that of EC particles, which included the secondary species of $\mathrm{NO}_{2}^{-}, \mathrm{NO}_{3}^{-}$, and $\mathrm{HSO}_{4}^{-}$, thus indicating the aging process of the particles. The OC particles were possibly emitted by biomass burning, fossil fuel combustion, cooking, vehicle emission, and secondary formation (Zhang et al., 2015).

HOC, which constituted $5.3 \%$ of the total particles, had signals of high-molecular-weight organic species, such as $\mathrm{C}_{12} \mathrm{H}_{8}{ }^{+}$(m/z of 152), $\mathrm{C}_{13} \mathrm{H}_{9}^{+}$(m/z of 165), $\mathrm{C}_{15} \mathrm{H}_{9}{ }^{+}(\mathrm{m} / \mathrm{z}$ of 189), and $\mathrm{C}_{18} \mathrm{H}_{10}{ }^{+}(\mathrm{m} / \mathrm{z}$ of 226) (Fig. 3(d)), which are generally recognized as polycyclic aromatic hydrocarbons (PAHs). PAHs in Ningbo are primarily contributed by traffic emissions but other sources include biomass burning and coal combustion (Xu et al., 2016).

\section{Levoglucosan Particles}

LEV particles constituted $3.7 \%$ of the total particles. LEV ion fragments (Fig. 3(e)), such as $\mathrm{CHO}_{2}^{-}(\mathrm{m} / \mathrm{z}$ of -45$)$, $\mathrm{C}_{2} \mathrm{H}_{3} \mathrm{O}_{2}^{-}$(m/z of -59$)$, and $\mathrm{C}_{3} \mathrm{H}_{5} \mathrm{O}_{2}^{-}$( $\mathrm{m} / \mathrm{z}$ of -73$)$, were unique biomass burning tracers for particle mass spectrometry (Chen et al., 2016). The positive and negative spectra of LEV particles were similar to those of HOC particles, indicating that LEV and HOC particles may have similar sources. The polar plots (Fig. S2) confirm this association.

\section{K-rich Particles}

K-rich particles constituted $22.3 \%$ of the total particles. The average positive mass spectrum of K-rich particles exhibited a peak of $\mathrm{K}^{+}$(m/z of 39/41) (Fig. 3(f)). In the negative mass spectrum, peaks of nitrate $(\mathrm{m} / \mathrm{z}$ of -46 or $-62)$, sulfate (m/z of -97$), \mathrm{CN}^{-}(\mathrm{m} / \mathrm{z}$ of -26$)$, and $\mathrm{Cl}^{-}(\mathrm{m} / \mathrm{z}$ of -35$)$ were pronounced. $\mathrm{K}^{+}$has been identified as a tracer for particles emitted by biomass burning (Hleis et al., 2013; Zhang et al., 2013). Potassium is the dominant species in SPAMS and is present in all kinds of particles. Its polar plot shows a similar distribution with EC in Fig. S2.

\section{Heavy Metal Particles}

HMs, which accounted for $4.2 \%$ of analyzed particles, were characterized by intense ion peaks from metals (Fig. 3(g)), such as $\mathrm{V}^{+}$(m/z of 51), $\mathrm{Pb}^{+}$(m/z of 206/207/208), $\mathrm{Fe}^{+}(\mathrm{m} / \mathrm{z}$ of $54 / 56), \mathrm{Mn}^{+}$(m/z of 55$)$, and $\mathrm{Zn}^{+}(\mathrm{m} / \mathrm{z}$ of 64/66/68). In addition to alkali metal ions, $\mathrm{Fe}^{+}$and $\mathrm{Pb}^{+}$ dominated the positive mass spectrum. The oxidation of molten iron emits $\mathrm{Fe}^{+}, \mathrm{Pb}^{+}, \mathrm{K}^{+}, \mathrm{Na}^{+}$, and $\mathrm{Cl}^{+}$(Dall'Osto et al., 2008). In previous studies, $\mathrm{V}^{+}$( $\mathrm{m} / \mathrm{z}$ of 51) was associated with heavy fuel oil combustion, such as emissions from vehicle exhaust (Sodeman et al., 2005) and ships in particular (Ault et al., 2010). The polar plot of HM (in Fig. S2) indicates that the HMs come from local emissions.

\section{Na-rich Particles}

Na-rich particles comprised $3.4 \%$ of analyzed particles and included strong $\mathrm{Na}^{+}$(m/z of 23 ) peaks; relatively weak $\mathrm{K}^{+}\left(\mathrm{m} / \mathrm{z}\right.$ of 39/41) signals; and less intense $\mathrm{NH}_{4}^{+}(\mathrm{m} / \mathrm{z}$ of 18$)$, $\mathrm{Na}_{2} \mathrm{O}^{+}(\mathrm{m} / \mathrm{z}$ of 62$)$, and $\mathrm{Na}_{2} \mathrm{Cl}^{+}(\mathrm{m} / \mathrm{z}$ 81) signals (Fig. 3(i)). Previous studies have indicated that approximately $4.2 \%$ of the $\mathrm{PM}_{2.5}$ concentration in urban sites in Ningbo comprised sea salt particles (Xiao et al., 2012). The most intense peaks of $\mathrm{Na}^{+}$indicate that sea salt may be the primary source of Na-rich particles. The abundance of Na-rich 

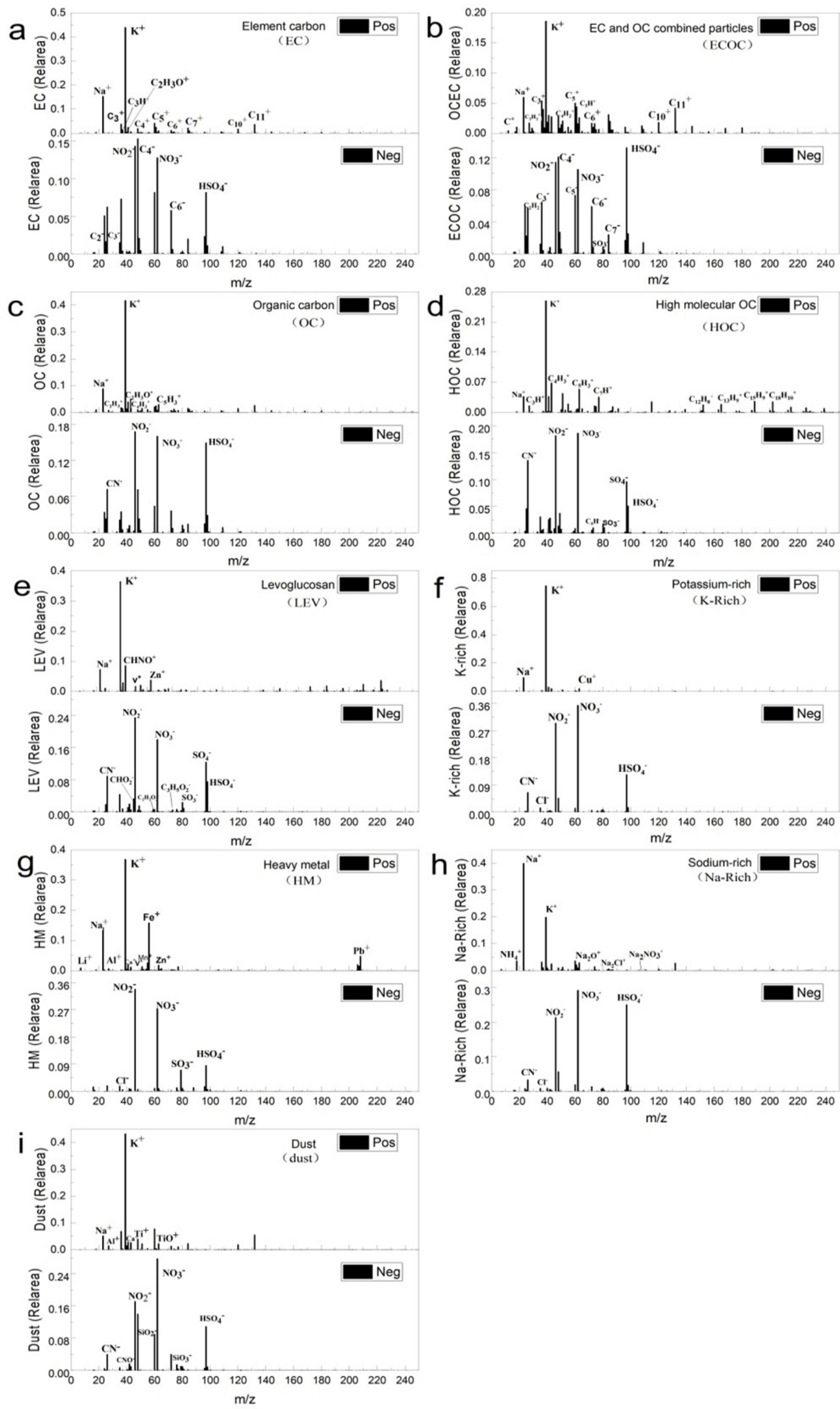

Fig. 3. Average mass spectra of the 9 particle types. 
Table 1. Number count and fraction of identified single particle classes in Ningbo.

\begin{tabular}{lll}
\hline Type & Number count & Number fraction \\
\hline EC & 169,559 & $46.90 \%$ \\
ECOC & 4,338 & $1.20 \%$ \\
OC & 23,861 & $6.60 \%$ \\
HOC & 19,161 & $5.30 \%$ \\
LEV & 13,377 & $3.70 \%$ \\
K-rich & 80,622 & $22.30 \%$ \\
HM & 15,184 & $4.20 \%$ \\
Na-rich & 12,292 & $3.40 \%$ \\
Dust & 10,846 & $3.00 \%$ \\
Other & 12,293 & $3.40 \%$ \\
\hline
\end{tabular}

particles shows a different distribution from other types (in Fig. S2). Furthermore, chloride was replaced by nitrate during transportation (Gard et al., 1998), and evident nitrate signals in the negative mass spectrum reflected the degree of the aging process. The results indicate that Na-rich particles are emitted from the regional transport of sea salt.

\section{Dust Particles}

Dust comprised $3.0 \%$ of the analyzed particles. The positive peaks of dust in Fig. 3(i) indicate the presence of $\mathrm{Na}^{+}(\mathrm{m} / \mathrm{z}$ of 23$), \mathrm{Al}^{+}$(m/z of 27$), \mathrm{Ca}^{+}(\mathrm{m} / \mathrm{z}$ of 40$), \mathrm{Ti}^{+}(\mathrm{m} / \mathrm{z}$ of 48$)$, and $\mathrm{TiO}^{+}(\mathrm{m} / \mathrm{z}$ of 64$)$. Nitrate $(\mathrm{m} / \mathrm{z}$ of $-46 / 62)$, sulfate $(\mathrm{m} / \mathrm{z}$ of -97$), \mathrm{CN}^{-}(\mathrm{m} / \mathrm{z}$ of -26$), \mathrm{SiO}_{2}^{-}(\mathrm{m} / \mathrm{z}$ of -60$)$, and $\mathrm{SiO}_{3}{ }^{-}(\mathrm{m} / \mathrm{z}$ of -76$)$ were present in the negative mass spectrum. The average negative spectrum of soil dust was mixed with silicate-related peaks (Silva et al., 2000). In this study, dust particles were a suitable tracer for soil dust.

\section{Mixing State of Major Particle Types}

Fig. 4 shows the mixing of major particle types with primary and secondary species with the particle sizes of $0.4-0.8,0.8-1.2$, and $1.2-1.6 \mu \mathrm{m}$. Previous studies have shown that chloride ions come from biomass burning and industrial activities (Zauscher et al., 2013; Ma et al., 2016). In this study, $62.6 \%$ of LEV and $35.5 \%$ of $\mathrm{HMs}$ in 0.4-1.6- $\mu \mathrm{m}$ particles were strongly associated with $\mathrm{Cl}^{-}$, and approximately $50 \%$ of OC particles comprised chloride (Fig. 4). Chloride is rarely present in organic particles
(Moffet et al., 2008). Weaker correlations between chloride and carbonaceous particles were observed in $\mathrm{Xi}$ 'an and Guangzhou (Zhang et al., 2015; Chen et al., 2016). A strong association was observed between OC particles and chloride, which indicated chlorine and OC particles may have the same sources.

All particles comprised more nitrate than sulfate in Fig. 4. More than $90 \%$ of major particles, excluding dust, comprised nitrate in the range of $0.4-1.6 \mu \mathrm{m}$. As the monitoring site was located in a high-traffic area, local traffic discharged a considerable amount of gaseous precursors, such as $\mathrm{NO}$ and $\mathrm{NO}_{2}$. Inorganic particles included fewer sulfates than carbonaceous particles (Fig. 4). The highest mixing fraction of sulfate was mostly observed in the smallest size range $(0.4-0.8 \mu \mathrm{m})$. The particle mixing trend with nitrate and ammonium was inconsistent. Hu et al. (2018) speculated that nitrate in major particle types is primarily formed through the condensation of nitric acid and not ammonium nitrate. Another possibility is the result of an instrumental bias since SPAMS has high sensitivity of nitrate. Moreover, in this study, a significant positive correlation was observed between the nitrate mixing fraction and particle mass concentration (Fig. 5), which indicates that the transformation of nitrate precursors is correlated with particle pollution.

Phosphate is considered a marker of heavy-duty diesel vehicles (Spencer et al., 2006). However, in this study, the mixing fraction of most traffic-related EC was less than $2 \%$. Therefore, $37.7 \%$ of HMs and $40.0 \%$ of LEV in the range of 1.2-1.6 $\mu \mathrm{m}$ (Fig. 4(c)) suggested the presence of another source of phosphate in Ningbo. $\mathrm{C}_{2} \mathrm{H}_{3} \mathrm{O}^{+}$with a strong peak in $\mathrm{OC}$ and $\mathrm{LEV}$ particles was selected to represent secondary organic markers (Moffet et al., 2008). The abundance of oxalate in inorganic particles, such as dust, HM, and Na-rich and K-rich particles, showed a higher mixing fraction in the size range of $0.4-0.8 \mu \mathrm{m}$ than other size ranges (Fig. 4(a)). Oxalate is formed through aqueous and heterogeneous reactions (Ervens et al., 2011; Zhang et al., 2014), which indicates that the gas-to-particle transformation of inorganic particles is significant for the size range of $0.4-0.8 \mu \mathrm{m}$.

Sulfate and nitrate are significant secondary inorganic ions in fine particles (Chen et al., 2017). Although the two species have different origins, in many cities, a positive a

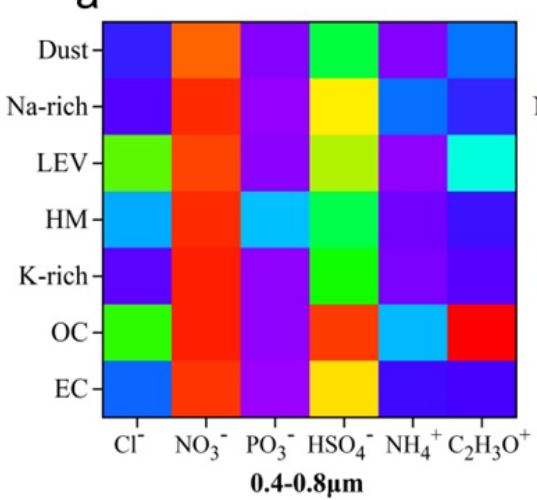

b

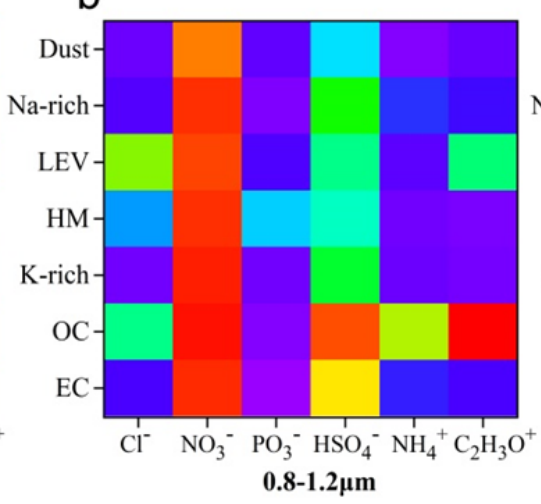

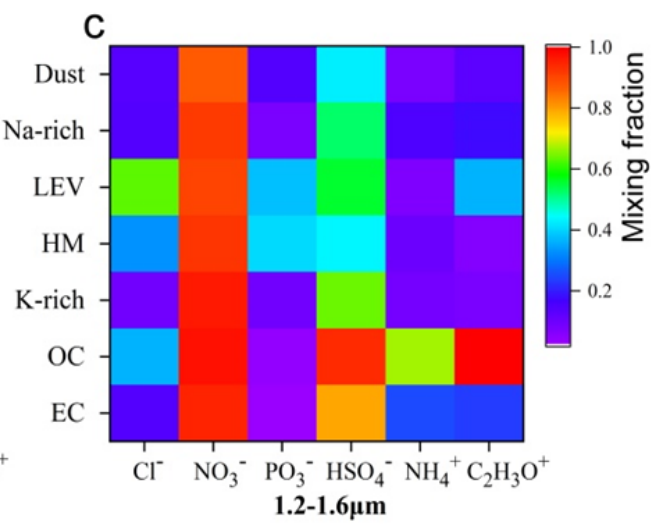

Fig. 4. Mixing state of primary and secondary species in the major particle types. 

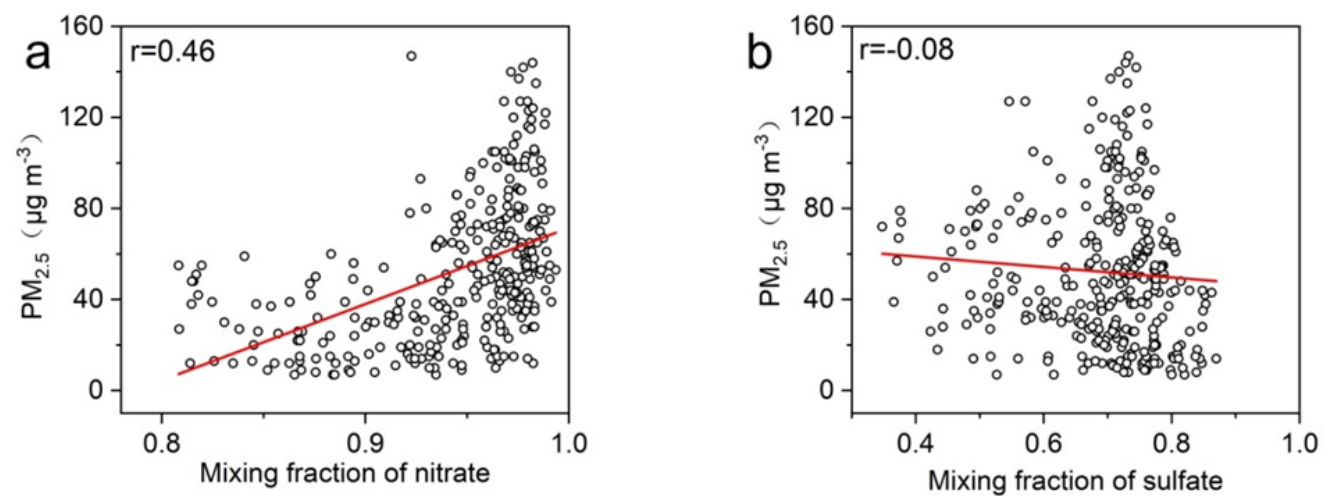

Fig. 5. Scatterplots between mixing fraction of (a) nitrate and (b) sulfate, and $\mathrm{PM}_{2.5}$ mass concentration.

correlation is observed between their mass concentrations (Wakamatsu et al., 1996; Pathak et al., 2009). However, Kong et al. (2014) reported that in Shanghai, the nitrate mass fraction is negatively correlated with the sulfate mass fraction, and they revealed that meteorological conditions, aerosol acidity, and wet deposition affect the correlation between sulfate and nitrate. The online SPAMS method enabled the observation of the mixing fraction of sulfate and nitrate (Fig. 6). Comparing the mass fraction correlation, the correlation between nitrate and sulfate in the internal state of particles is attributed to different particle sources and the stage of aging processes. In Periods II and III, strong negative and weak negative correlations were found (Jacob, 1988), respectively. Considering the dominant northeast wind observed in Periods II and III (Fig. 2), regional transport from the northeast may contribute to the negative correlation.

\section{Particle Characteristics during Pollution Episodes}

Fig. 2 presents the temporal variation in WS, WD, temperature, $\mathrm{RH}, \mathrm{PM}_{2.5}$, and hit particles collected when monitoring air pollution. According to the Technical Regulation on Ambient Air Quality Index (on trial) (HJ 633-2012), the individual air quality index value of 150 200 for $\mathrm{PM}_{2.5}$ represents moderate air pollution, and the corresponding concentration range was $115-150 \mu \mathrm{g} \mathrm{m}^{-3}$. The hourly concentrations of the SPAMS number indicated a strong correlation $(\mathrm{R}=0.83)$ with particle mass concentration. Fig. 7 shows the number, concentration, and size distribution of hit particles. Particle number concentration was found to be increased from 0.4 to $0.6 \mu \mathrm{m}$, accompanied by high mass concentration at the same time. In a previous study, similar trends were observed in Guangdong Province; however, the dominant size ranged from 0.6 to $0.8 \mu \mathrm{m}$ (Chen et al., 2014). Fine particles with a size ranging from 0.4 to $0.6 \mu \mathrm{m}$ play a critical role in the generation of particle pollution in this region.

Fig. 8 presents the temporal number concentrations of different particle types during the three periods. All particle types were observed during the three periods, and the number concentrations of the nine types of particles changed moderately during the sampling period. In Period I, EC particles were the largest category among all particles. The number concentration of OC (including HOC) and LEV particles under moderate pollution was higher than those under a clean environment, particularly that of OC particles. $\mathrm{PM}_{2.5}$ mass concentration increased with the increasing particle number concentration in the size range of $0.4-0.6$ $\mu \mathrm{m}$ and $0.5-0.7 \mu \mathrm{m}$ (Fig. 7). On the basis of the fraction variations in EC particles in Period I, a correlation analysis of the linear regressions between hourly time series for smaller EC particles $(<0.45 \mu \mathrm{m})$, medium-size EC particles $(0.45-0.6 \mu \mathrm{m})$, and $\mathrm{RH}$ was made in Table S1. RH was significantly positively correlated with medium-size EC and significantly negatively correlated with smaller size EC. From S3, the medium size EC particles show the same distribution wind rose with smaller size EC particles, indicating there is no more regional transport. With higher humidity and lower boundary layer temperatures at night, particles can capture more soluble gases, such as $\mathrm{SO}_{2}$ and $\mathrm{NO}_{x}$, thus accumulating $\mathrm{PM}_{2.5}$ (Yang et al., 2017b). Therefore, the two highest values of $\mathrm{PM}_{2.5}$ mass concentration at night are primarily attributed to secondary formation. Fig. 10(a) shows that high concentrations of particles were observed when the WS was lower than $2 \mathrm{~m} \mathrm{~s}^{-1}$. During Period I, local emission and secondary formation caused aerosol pollution.

Because of stagnant conditions, the variations in size distribution and chemical composition in Period II showed the same trends as those in Period I on the nights of 2-4 January 2017. However, the number concentration of K-rich and OC particles suddenly increased at noon on 2 January 2017, when $\mathrm{PM}_{2.5}$ mass concentration was moderate. The WS was then strong, and the northern wind was prevailing (Fig. 2). Fig. 3 shows that in the negative mass spectrum of K-rich particles, the secondary inorganic ions of $\mathrm{NO}_{2}^{-}(\mathrm{m} / \mathrm{z}$ of -46$), \mathrm{NO}_{3}^{-}$(m/z of -62$)$, and $\mathrm{HSO}_{4}^{-}(\mathrm{m} / \mathrm{z}$ of -97$)$ had the strongest signal intensity among major particle species, which may be attributed to the aging process. On the night of 3 January 2017, a small peak in $\mathrm{PM}_{2.5}$ mass concentration was observed when the northern wind was prevailing, which indicated that transport from the north induced particle pollution. In Fig. 10(b), high particle number concentrations occurred under the northwestern wind with a high WS in Period II. The aforementioned result indicates that stagnant meteorological conditions and regional transport from the north generated pollution.

In Period III, $\mathrm{PM}_{2.5}$ mass concentrations reached a peak at night on 10 January 2017. Probably because of the 

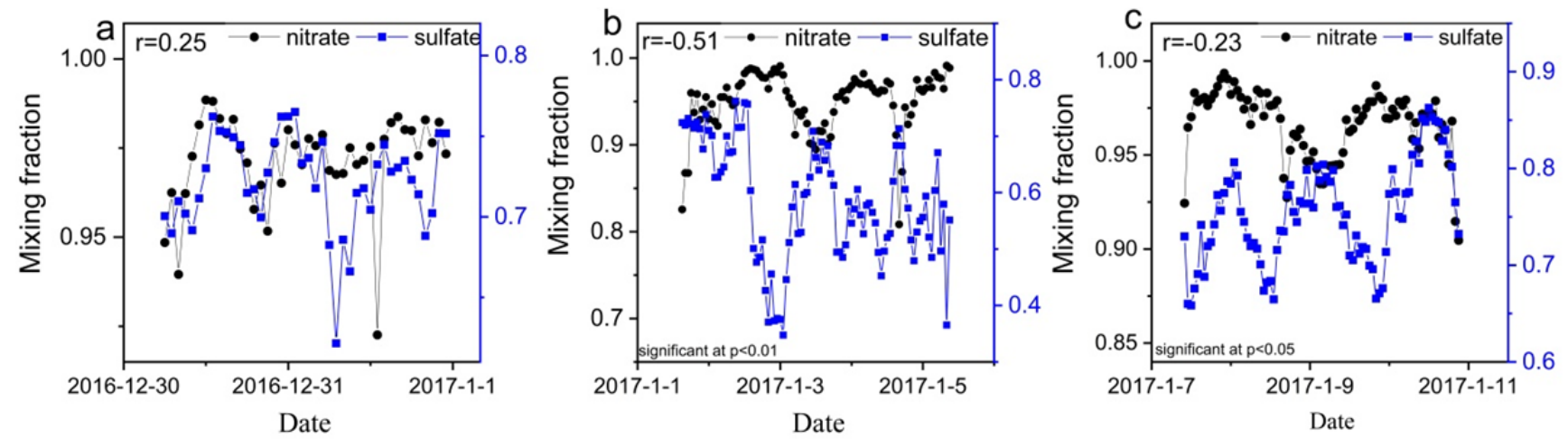

Fig. 6. Hourly mixing fraction of nitrate and sulfate during Period (a) I, (b) II, and (c) III.

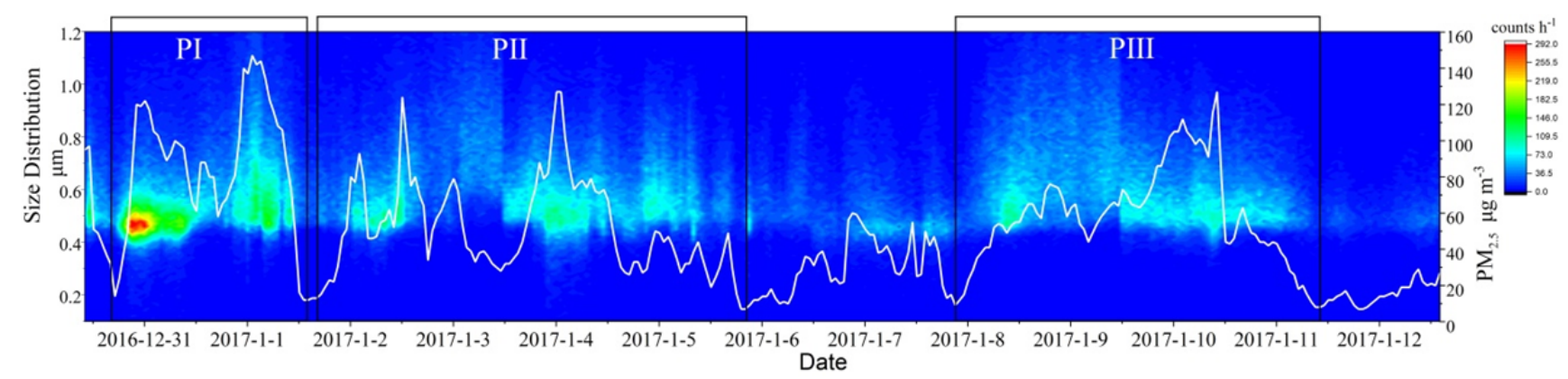

Fig. 7. Temporal evolution of hit particle number size distribution and $\mathrm{PM}_{2.5}$ mass concentration (white line).

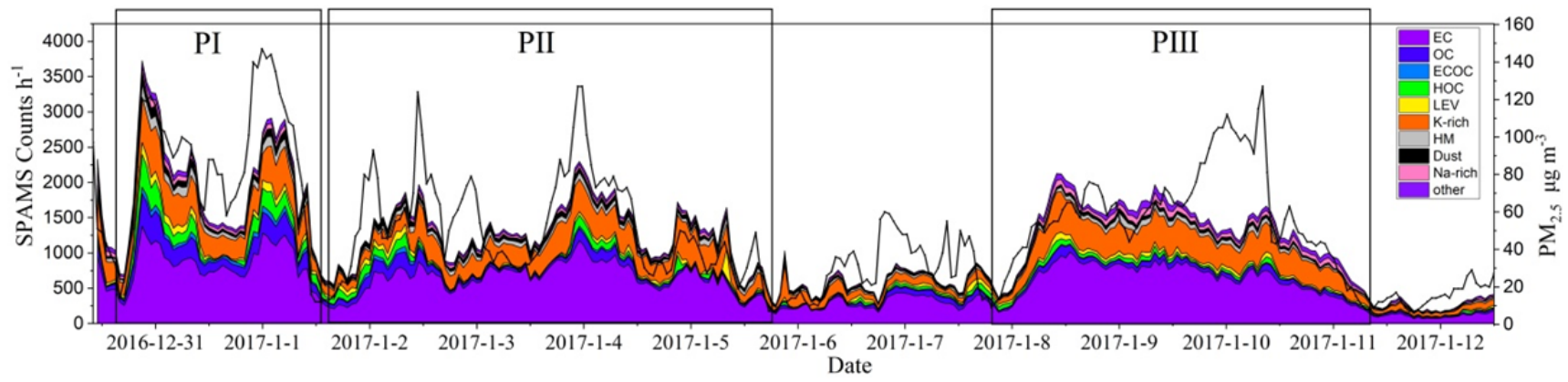

Fig. 8. Temporal number concentration of 10 particle types and $\mathrm{PM}_{2.5}$ mass concentration (black line).

comprehensive influence of meteorological conditions and photochemical reactions at noon, particle mass concentration increased rapidly during daytime after a brief decline. The number concentrations of Na-rich and K-rich particles in Period III were higher than those in the other two periods (I and II). On the basis of the previous analysis, Na-rich particles were attributed to marine transport. Fig. 10(c) shows particle abundance under the northwest wind at speeds of 4-6 $\mathrm{m} \mathrm{s}^{-1}$, indicating that regional transport from the northwest contributed to pollution.

\section{CONCLUSIONS}

This study identified the characteristics of single particles from 30 December 2016 to 12 January 2017, in the urban area of Ningbo. 361,533 particles were categorized using ART-2a analysis and then divided into 10 classes, namely EC, OC, ECOC, HOC, LEV, K-rich, HM, Na-rich, dust, and other particles. Excluding the last, these classes displayed secondary species peaks, indicating that the particles underwent an aging process. The most abundant type of particle during the observation period was composed of EC. Smaller EC particles represented local emission, whereas larger EC particles were associated with regional transport.

Particles within the size range of $0.4-0.8 \mu \mathrm{m}$, which were internally mixed with the high-fraction secondary species, significantly affected the atmospheric pollution. The trends of the number concentrations and mixing states for the secondary species indicated severe secondary aerosol pollution. The $\mathrm{PM}_{2.5}$ concentration exhibited obvious diurnal variations during Periods I and II of the sampling period; furthermore, high concentrations were frequently observed at night during stagnant atmospheric conditions. Thus, meteorological conditions, secondary conversion, and regional transport were partially responsible for the pollution in Ningbo. 

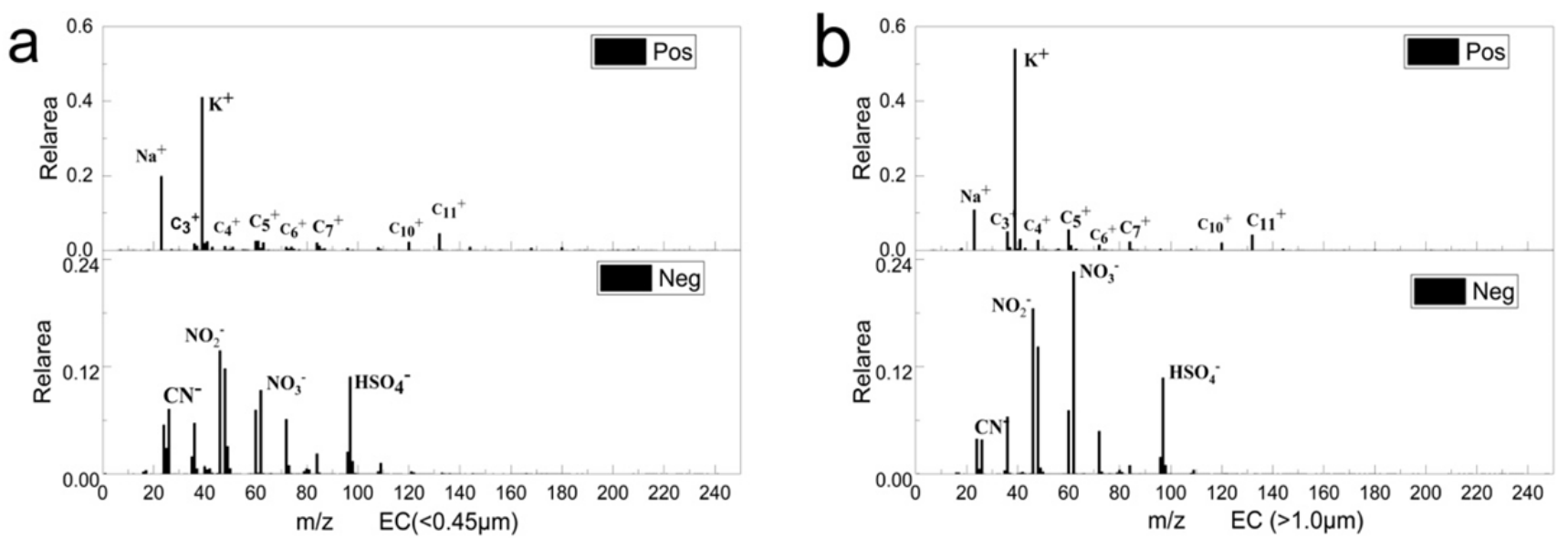

Fig. 9. Average mass spectra of (a) smaller size EC and (b) larger size EC particles.

a

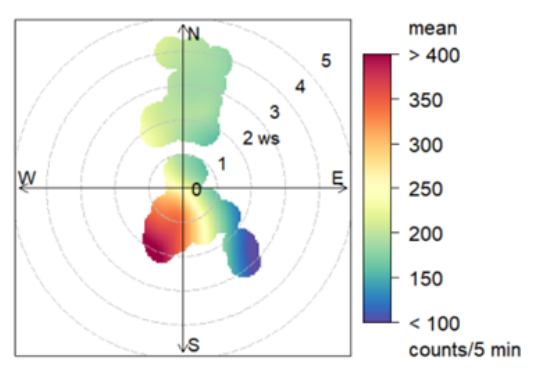

$\mathrm{b}$

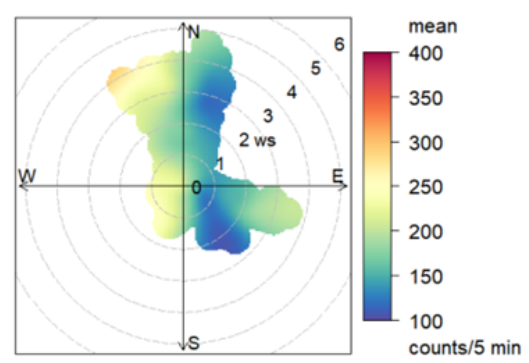

$\mathrm{C}$

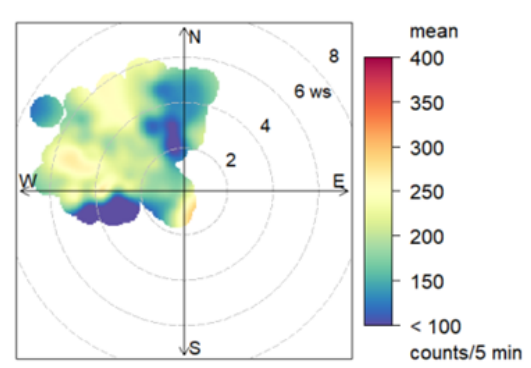

Fig. 10. Polar plots of hit particles in Periods (a) I, (b) II, and (c) III.

\section{ACKNOWLEDGMENTS}

This work was financially supported by the Ministry of Science and Technology of China (Grant No. 2016YFE0112200) and the National Natural Science Foundation of China (Grant No. 21607056).

\section{SUPPLEMENTARY MATERIAL}

Supplementary data associated with this article can be found in the online version at http://www.aaqr.org.

\section{REFERENCES}

Ault, A.P., Gaston, C.I., Wang, Y., Dominguez, G., Thiemens, M.H. and Prather, K.A. (2010). Characterization of the single particle mixing state of individual ship plume events measured at the Port of Los Angeles. Environ. Sci. Technol. 44: 1954-1961.

Cahill, J.F., Suski, K., Seinfeld, J.H., Zaveri, R.A. and Prather, K.A. (2012). The mixing state of carbonaceous aerosol particles in northern and southern California measured during CARES and CalNex 2010. Atmos. Chem. Phys. 12: 10989-11002.

Cai, J., Zheng, M., Yan, C.Q., Fu, H.Y., Zhang, Y.J., Li, M., Zhou, Z. and Zhang, Y.H. (2015). Application and progress of single particle aerosol time-of-flight mass spectrometer in fine particulate matter research. Chin. J. Anal. Chem. 43: 765-774.
Chai, P.F. and Zheng, W.H. (2018). Characteristics of air pollutants in Ningbo, 2016. Preventive Med. 30: 130 133. (in Chinese)

Chen, D., He, J. and Zhang, G. (2014). A preliminary study on the characteristics of fine particle pollution characteristics for different weather type in the Guangdong atmospheric supersite. Geochimic 43: 217223.

Chen, F., Zhang, X.H., Zhu, X.S., Zhang, H., Gao, J.X. and Hopke, P.K. (2017). Chemical characteristics of $\mathrm{PM}_{2.5}$ during a 2016 winter haze episode in Shijiazhuang, China. Aerosol Air Qual. Res. 17: 368-380.

Chen, Y., Cao, J., Huang, R., Yang, F., Wang, Q. and Wang, Y. (2016). Characterization, mixing state, and evolution of urban single particles in Xi'an (China) during wintertime haze days. Sci. Total Environ. 573: 937-945.

Cheng, Z., Wang, S., Fu, X., Watson, J.G., Jiang, J., Fu, Q., Chen, C., Xu, B., Yu, J., Chow, J.C. and Hao, J. (2014). Impact of biomass burning on haze pollution in the Yangtze River Delta, China: A case study in summer 2011. Atmos. Chem. Phys. 14: 4573-4585.

Dall'Osto, M., Booth, M.J., Smith, W., Fisher, R. and Harrison, R.M. (2008). A study of the size distributions and the chemical characterization of airborne particles in the vicinity of a large integrated steelworks. Aerosol Sci. Technol. 42: 981-991.

Ervens, B., Turpin, B.J. and Weber, R.J. (2011). S Secondary organic aerosol formation in cloud droplets and aqueous particles (aqSOA): A review of laboratory, 
field and model studies. Atmos. Chem. Phys. 11: 1106911102.

Fu, H., Zhang, M., Li, W., Chen, J., Wang, L., Quan, X. and Wang, W. (2012). Morphology, composition and mixing state of individual carbonaceous aerosol in urban Shanghai. Atmos. Chem. Phys. 12: 693-707.

Fu, H., YAn, C., Zheng, M., Cai, J., Li, X., Zhang, Y., Zhou, Z., Fu, Z., Li, M., Li, L. and Zhang, Y. (2014). Application of on-line single particle aerosol mass spectrometry (SPAMS) for studying major components in fine particulate matter. Environ. Sci. 35: 4070-4077. (in Chinese)

Gao, L., Jia, G., Zhang, R., Che, H., Fu, C., Wang, T., Zhang, M., Jiang, H. and Yan, P. (2011). Visual range trends in the Yangtze River Delta Region of China, 1981-2005. J. Air Waste Manage. Assoc. 61: 843-849.

Gard, E.E., Kleeman, M.J., Gross, D.S., Hughes, L.S., Allen, J.O., Morrical, B.D., Fergenson, D.P., Dienes, T., M, E.G., Johnson, R.J., Cass, G.R. and Prather, K.A. (1998). Direct observation of heterogeneous chemistry in the atmosphere. Science 279: 1184-1187.

Giorio, C., Tapparo, A., Dall'Osto, M., Harrison, R.M., Beddows, D.C.S., Di Marco, C. and Nemitz, E. (2012). Comparison of three techniques for analysis of data from an Aerosol Time-of-Flight Mass Spectrometer. Atmos. Environ. 61: 316-326.

Giorio, C., Tapparo, A., Dall'Osto, M., Beddows, D.C., Esser-Gietl, J.K., Healy, R.M. and Harrison, R.M. (2015). Local and regional components of aerosol in a heavily trafficked street canyon in central London derived from PMF and cluster analysis of single-particle ATOFMS spectra. Environ. Sci. Technol. 49: 3330-3340.

Hleis, D., Fernandez-Olmo, I., Ledoux, F., Kfoury, A., Courcot, L., Desmonts, T. and Courcot, D. (2013). Chemical profile identification of fugitive and confined particle emissions from an integrated iron and steelmaking plant. J. Hazard. Mater. 250-251: 246-255.

Hu, R., Wang, H., Yin, Y., Chen, K., Zhu, B., Zhang, Z., Kang, H. and Shen, L. (2018). Mixing state of ambient aerosols during different fog-haze pollution episodes in the Yangtze River Delta, China. Atmos. Environ. 178: 110.

Jacob, C. (1988). Statistical power analysis for the behavioral sciences (2nd ed.). Lawrence Erlbaum Associates, New York.

Kanakidou, M., Seinfeld, J.H., Pandis, S.N., Barnes, I., Dentener, F.J., Facchini, M.C., Van Dingenen, R., Ervens, B., Nenes, A., Nielsen, C.J., Swietlicki, E., Putaud, J.P., Balkanski, Y., Fuzzi, S., Horth, J., Moortgat, G.K., Winterhalter, R., Myhre, C.E.L., Tsigaridis, K., Vignati, E., Stephanou, E.G. and Wilson, J. (2005). Organic Aerosol and global climate modelling: A review. Atmos. Chem. Phys. 5: 1053-1123.

Kong, L., Yang, Y., Zhang, S., Zhao, X., Du, H., Fu, H., Zhang, S., Cheng, T., Yang, X., Chen, J., Wu, D., Shen, J., Hong, S. and Jiao, L. (2014). Observations of linear dependence between sulfate and nitrate in atmospheric particles. J. Geophys. Res. 119: 341-361.

Konieczynski, J., Zajusz-Zubek, E. and Jablonska, M.
(2012). The release of trace elements in the process of coal coking. Sci. World J. 2012: 294927.

Li, L., Huang, Z., Dong, J., Li, M., Gao, W., Nian, H., Fu, Z., Zhang, G., Bi, X., Cheng, P. and Zhou, Z. (2011). Real time bipolar time-of-flight mass spectrometer for analyzing single aerosol particles. Int. J. Mass Spectrom. 303: 118-124.

Li, Y.J., Sun, Y., Zhang, Q., Li, X., Li, M., Zhou, Z. and Chan, C.K. (2017). Real-time chemical characterization of atmospheric particulate matter in China: A review. Atmos. Environ. 158: 270-304.

Ma, L., Li, M., Huang, Z., Li, L., Gao, W., Nian, H., Zou, L., Fu, Z., Gao, J., Chai, F. and Zhou, Z. (2016). Real time analysis of lead-containing atmospheric particles in Beijing during springtime by single particle aerosol mass spectrometry. Chemosphere 154: 454-462.

Moffet, R.C., de Foy, B., Molina, L.T., Molina, M.J. and Prather, K.A. (2008). Measurement of ambient aerosols in northern Mexico City by single particle mass spectrometry. Atmos. Chem. Phys. 8: 4499-4516.

Pathak, R.K., Wu, W.S. and Wang, T. (2009). Summertime $\mathrm{PM}_{2.5}$ ionic species in four major cities of China: Nitrate formation in an ammonia-deficient atmosphere. Atmos. Chem. Phys. 9: 1711-1722.

Silva, P.J., Carlin, R.A. and Prather, K.A. (2000). Single particle analysis of suspended soil dust from Southern California. Atmos. Environ. 34: 1811-1820.

Sodeman, D.A., Toner, S.M. and Prather, K.A. (2005). Determination of single particle mass spectral signatures from light-duty vehicle emissions. Environ. Sci. Technol. 39: 4569-4580.

Spencer, M.T., Shields, L.G., Sodeman, D.A., Toner, S.M. and Prather, K.A. (2006). Comparison of oil and fuel particle chemical signatures with particle emissions from heavy and light duty vehicles. Atmos. Environ. 40: 5224-5235.

Taiwo, A.M., Harrison, R.M., Beddows, D.C.S. and Shi, Z. (2014). Source apportionment of single particles sampled at the industrially polluted town of Port Talbot, United Kingdom by ATOFMS. Atmos. Environ. 97: 155-165.

Tie, X., Wu, D. and Brasseur, G. (2009). Lung cancer mortality and exposure to atmospheric aerosol particles in Guangzhou, China. Atmos. Environ. 43: 2375-2377.

Toner, S.M., Sodeman, D.A. and Prather, K.A. (2006). Single particle characterization of ultrafine and accumulation mode particles from heavy duty diesel vehicles using aerosol time-of-flight mass spectrometry. Environ. Sci. Technol. 40: 3912-3921.

Wakamatsu, S., Utsunomiya, A., Jin Suk, H., Mori, A., Uno, I. and Uehara, K. (1996) Seasonal variation in atmospheric aerosols concentration covering northern Kyushu, Japan and Seoul, Korea. Atmos. Environ. 30: 2343-2354.

Wang, H., An, J., Shen, L., Zhu, B., Pan, C., Liu, Z., Liu, X., Duan, Q., Liu, X. and Wang, Y. (2014). Mechanism for the formation and microphysical characteristics of submicron aerosol during heavy haze pollution episode in the Yangtze River Delta, China. Sci. Total Environ. 490: 501-508. 
Wang, H., An, J., Shen, L., Zhu, B., Xia, L., Duan, Q. and Zou, J. (2016). Mixing state of ambient aerosols in Nanjing city by single particle mass spectrometry. Atmos. Environ. 132: 123-132.

Xiao, R., Takegawa, N., Kondo, Y., Miyazaki, Y., Miyakawa, T., Hu, M., Shao, M., Zeng, L.M., Hofzumahaus, A., Holland, F., Lu, K., Sugimoto, N., Zhao, Y. and Zhang, Y.H. (2009). Formation of submicron sulfate and organic aerosols in the outflow from the urban region of the Pearl River Delta in China. Atmos. Environ. 43: 37543763.

Xiao, Z., Bi, X. and Feng, Y. (2012). Source apportionment of ambient $\mathrm{PM}_{10}$ and $\mathrm{PM}_{2.5}$ in urban area of Ningbo City. Res. Environ. Sci. 25: 549-555.

Xu, J.S., Xu, H.H., Xiao, H., Tong, L., Snape, C.E., Wang, C.J. and He, J. (2016). Aerosol composition and sources during high and low pollution periods in Ningbo, China. Atmos. Res. 178-179: 559-569.

Yang, F., Chen, H., Du, J., Yang, X., Gao, S., Chen, J. and Geng, F. (2012). E Evolution of the mixing state of fine aerosols during haze events in Shanghai. Atmos. Res. 104-105: 193-201.

Yang, J., Ma, S., Gao, B., Li, X., Zhang, Y., Cai, J., Li, M., Yao, L., Huang, B. and Zheng, M. (2017a). Single particle mass spectral signatures from vehicle exhaust particles and the source apportionment of on-line $\mathrm{PM}_{2.5}$ by single particle aerosol mass spectrometry. Sci. Total Environ. 593-594: 310-318.

Yang, W.L., Wang, G.C. and Bi, C.J. (2017b). Analysis of long-range transport effects on $\mathrm{PM}_{2.5}$ during a short severe haze in Beijing, China. Aerosol Air Qual. Res. 17: 1610-1622.

Zauscher, M.D., Wang, Y., Moore, M.J., Gaston, C.J. and Prather, K.A. (2013). Air quality impact and physicochemical aging of biomass burning aerosols during the 2007 San Diego wildfires. Environ. Sci. Technol. 47: 7633-7643.

Zhang, G., Bi, X., Li, L., Chan, L.Y., Li, M., Wang, X.,
Sheng, G., Fu, J. and Zhou, Z. (2013). Mixing state of individual submicron carbon-containing particles during spring and fall seasons in urban Guangzhou, China: A case study. Atmos. Chem. Phys. 13: 4723-4735.

Zhang, G., Bi, X., He, J., Chen, D., Chan, L.Y., Xie, G., Wang, X., Sheng, G., Fu, J. and Zhou, Z. (2014). Variation of secondary coatings associated with elemental carbon by single particle analysis. Atmos. Environ. 92: 162-170.

Zhang, G., Han, B., Bi, X., Dai, S., Huang, W., Chen, D., Wang, X., Sheng, G., Fu, J. and Zhou, Z. (2015). Characteristics of individual particles in the atmosphere of Guangzhou by single particle mass spectrometry. Atmos. Res. 153: 286-295.

Zhang, Y., Tang, L., Yu, H., Wang, Z., Sun, Y., Qin, W., Chen, W., Chen, C., Ding, A., Wu, J., Ge, S., Chen, C. and Zhou, H.C. (2015). Chemical composition, sources and evolution processes of aerosol at an urban site in Yangtze River Delta, China during wintertime. Atmos. Environ. 123: 339-349.

Zhao, S., Chen, L., Yan, J. and Chen, H. (2017). Characterization of lead-containing aerosol particles in Xiamen during and after Spring Festival by singleparticle aerosol mass spectrometry. Sci. Total Environ. 580: 1257-1267.

Zhou, Y., Huang, X.H.H., Griffith, S.M., Li, M., Li, L., Zhou, Z., Wu, C., Meng, J., Chan, C.K., Louie, P.K.K. and Yu, J.Z. (2016). A field measurement based scaling approach for quantification of major ions, organic carbon, and elemental carbon using a single particle aerosol mass spectrometer. Atmos. Environ. 143: 300312.

Received for review, January 26, 2019

Revised, April 22, 2019

Accepted, June 27, 2019 